\title{
Effectively Engaging with Indigenous Communities through Multi-Methods Qualitative Data Collection and an Engaged Communications Plan
}

\author{
Lee A. Swanson, Joelena Leader \& Dazawray Landrie-Parker
}

\begin{abstract}
A research project on social and economic capacity building through Aboriginal entrepreneurship employed a highly engaged approach with communities in northern Saskatchewan, Canada. The involved communities were viewed as research partners, and the research team applied a comprehensive communications plan to provide community members with relevant and timely information about the project and summaries of its outcomes as those results emerged. The study was designed to empower those who traditionally had been viewed as participants on whom research could be conducted, and ensure that the research was instead conducted with and for them. This research project encouraged youth and adults to express their perspectives in new and engaging ways that gave them the opportunity to more meaningfully have their voices heard. One important outcome from engaging more with communities was that research team members felt more engaged with their own project.
\end{abstract}

KEYWords engagement; Indigenous; Aboriginal; community; engaged scholar; capacity building; entrepreneurship; research methods; qualitative method

A research initiative exploring social and economic capacity building through Aboriginal entrepreneurship in rural and relatively remote communities in the northern part of the Canadian province of Saskatchewan employed a multi-methods qualitative data collection approach. Additionally, this study implemented a comprehensive communications plan to engage with community members. This engagement strategy was designed to empower participants, including high school students, to express their perspectives through their own voices and according to their own unique viewpoints. It was also designed to ensure that the research was conducted with and for the communities instead of on them. This approach helped extend the research project and might improve the potential for funding to support further research on capacity building through Aboriginal entrepreneurship. This article provides a narrative description of the experiences of the research team members as they implemented an engagement plan with communities and the more than 380 research participants in the primarily Indigenous communities across northern Saskatchewan who participated in the first two phases of the research project.

In this article, the term Indigenous is used when referring specifically to the descendants of 
the original inhabitants of the region being discussed. Aboriginal is a broader term that also includes the Métis people, those who are descendants from both Indigenous people and from people who settled in that region after Europeans arrived in North America.

\section{Decolonizing Indigenous Research}

The arrival of European settlers in North America over five centuries ago marked the beginning of a period of colonialism that continues to shape the way that researchers view their work with Indigenous communities. There is a significant debate within the literature outlining the issues that arise with research involving Indigenous communities, particularly with the research process itself and the ways in which findings are presented (Chilisa, 2012). One criticism is that researchers often impose methodologies that frame research in a way that does not blend well with Indigenous concepts or knowledge and experiences. This calls for "the need to bring Indigenous methodologies into the research arena" (Chilisa, 2012, p. xv) and importantly, "non-Indigenous researchers need to be mindful of their part in knowledge creation, to be respectful and accountable to the communities they work with, and to ultimately contribute to an increased space within [all] research for Indigenous knowledge and methodologies" (Graeme, 2013, p. 513).

Smith's (2012) discussion on decolonization critiques positivistic research arguing for the need to find marginalization and to create spaces where Indigenous research agendas are developed. Western research brings a particular set of values and discourses that influence researcher interpretations; however, an Indigenous paradigm does not reject existing approaches. Instead, it seeks to decolonize the process whereby the research does not oppress or misrepresent Indigenous peoples, communities, or cultures. By applying decolonizing methodologies, researchers can position themselves "and their work in relation to the people for whom the research still counts” (L. T. Smith, 2012, p. 17). Researchers can do this by carrying out "bicultural research, partnership research and multi-disciplinary research" (p. 17) that includes Indigenous people in mutually beneficial ways with the goal of conducting research with and for Indigenous people instead of on Indigenous people (Koster, Baccar, \& Lemelin, 2012). This approach should improve the relevance of the research being conducted as it can decolonize the research and meaningfully involve Indigenous communities on their own terms and for their own benefit (First Nations Centre, 2007; Koster et al., 2012; Schnarch, 2004).

Wilson (2008) noted the perception that North American and Australian Indigenous peoples are among the most widely studied, but the research has often not

... been asked for, nor has it had any relevance for the communities being studied. People are accustomed to seeing researchers come into their communities, do whatever it is they do and leave, never to be heard from again. Because community members are for the most part excluded from the research process, they have become resentful of research in general. (Wilson, 2008, p. 15)

Engaged Scholar Journal: Community-Engaged Research, Teaching, and Learning 
From the project's beginning, the Building Northern Capacity through Aboriginal Entrepreneurship (BNCAE) the research team pledged to implement measures to conduct their research in a decolonizing manner. This approach involved ensuring that the people in the participating communities were included and consulted throughout the process, and would benefit from meaningful, timely, and accessible feedback from the research outcomes. The BNCAE research project was to be an engaging and engaged process that fostered collaborative partnerships with stakeholders throughout the region in which the study was conducted.

\section{Research Project Background and Context}

The process began in 2009 when three researchers at the University of Saskatchewan combined their expertise in Aboriginal engagement, community development, and entrepreneurship to begin addressing a research gap related to Aboriginal entrepreneurship. A fourth researcher joined this group in 2011 to form what would become the core faculty group of the BNCAE research team.

It was also in 2009 when one of these researchers launched the International Centre for Northern Governance and Development and became its initial director (another BNCAE researcher assumed the directorship a few years later). This marked the start of a comprehensive engagement initiative with Indigenous communities_-and with potential Scandinavian research colleagues — that would support the BNCAE research project.

In 2012, the researchers submitted a Social Sciences Humanities Research Council (SSHRC) grant application to fund a five-year study comparing social and economic capacity building through Aboriginal entrepreneurship in northern Saskatchewan with the experiences from northern Scandinavia. Those two regions are similar in many respects even though Saskatchewan is in a sub-Arctic region approximately 1,200 kilometers south of the Arctic Circle, and the region of concern in northern Norway, Sweden, and Finland is primarily north of the Arctic Circle. The communities in both regions are mostly rural and relatively remote, many have largely Indigenous populations, and some are heavily influenced by natural resource extractive industries located nearby. In the regions under consideration in Saskatchewan and Scandinavia, the climate and geography are also similar. For this article, we are not addressing the Scandinavian component of the BNCAE project.

An important element in this application was its focus on meaningfully engaging with local people in northern Saskatchewan communities as research partners. It also indicated a commitment to embrace the results from a report based on a SSHRC dialogue that sought to "capture as accurately, sensitively and pragmatically as possible the many voices, perspectives and suggestions brought to bear on the process of developing an Aboriginal Research Agenda for SSRHC” (McNaughton \& Rock, 2003, p. 1).

The application also outlined a knowledge mobilization plan that included a communications plan that would make the research findings accessible in a timely manner and in a form that would be useful for the residents of northern Saskatchewan, the primary region in which the research would occur. 
The SSHRC grant request was approved in 2013. By mid-2014, the researchers had assembled a research team, completed the initial project planning, and launched Phase One of the study. Phase One involved formally interviewing six targeted individuals from across northern Saskatchewan who had extensive experience in community development, and consulting with several others regarding how to best engage with communities and participants for the next phase. The results from Phase One included insights, such as the need to ask the youth in northern communities for their perspectives and to better understand the undocumented economy, which led to enhancements to the plans for Phase Two. Phase Two ran through 2015 and into the first months of 2016 and included qualitative data collection activities in seven different northern Saskatchewan communities involving approximately 200 high school students, 150 adult community members, and another 24 Photovoice participants.

One of the first activities during the planning phase in 2014, designed in part to solidify the commitment to meaningfully engage Indigenous communities, was to expand the research question into a full research statement along with detailed descriptions of what each part of the statement meant to the research team. The research statement follows:

\begin{abstract}
We are using participatory research methods to define, describe, and assess the past, current, and evolving states of the entrepreneurial ecosystem in Northern Saskatchewan as it has and is contributing to social and economic capacity building in relation to local concepts of 'the good life', wellbeing, and prosperity. This is a comparative study with Northern Scandinavia.
\end{abstract}

This statement represents the research team's commitment to viewing capacity building through the lens of the local people, who might or might not see it as benefiting them. The team wanted to better understand what types of lives people in the communities aspired to have as represented by the local concepts of the good life, wellbeing, and prosperity. The good life, or miyo-pimatisiwin in one dialect of the Cree language, one of the three main Aboriginal languages in northern Saskatchewan (Dene and Michif are the others), is an important Indigenous concept in the region. The word pimatisiwin refers to "ancient knowledge [of] community life, well-being, and sharing of values (Settee, 2013, p. 6); "For Indigenous peoples, land, food, and health are key components of pimatisiwin, from the Cree root word pimatisi 'to be alive"' (p. 3). It is the interconnectedness of these components that work together to promote pimatisinin.

Although not explicitly stated in the research statement, the BNCAE team also designed questions to better understand what the term poverty meant to the members of the communities being studied. This was meant to provide additional context to respondents' perspectives on the good life, wellbeing and prosperity. It also provided respondents with an opportunity to define poverty as they saw it because local characteristics, particularly in rural areas, appear to affect the nature of poverty. Among the regional attributes that shape what poverty looks like in a particular region are "its natural environment, its economic structure, its public and community institutions, its existing social norms and cultural environment, and the demographic characteristics of its population" (Blank, 2005, p. 442).

Engaged Scholar Journal: Community-Engaged Research, Teaching, and Learning 
The BNCAE team felt that measures of poverty generated by Statistics Canada, using quantitative data collected through formal means and primarily based upon documented economic activity, might not reflect how northerners perceived poverty in their communities. Poverty is usually defined as the inability to meet basic needs relative to the norms of the broader community. The Low-Income Cut-Off (LICO) measurement used by Statistics Canada represents the income level at which a family must spend a greater proportion of its income on basic needs and necessities than the average same-sized family (Statistics Canada, 2015).

A characteristic of many of the communities in Saskatchewan's north is that much of the economic activity occurs as part of the undocumented giving, sharing, and trading economy. A common example is when a local hunter shoots a moose and shares the meat with community members. Since those people do not need to purchase meat from a registered business, the economic benefits derived from sharing the moose meat are undocumented. This might mean that the only available measures indicate that some communities have high levels of poverty when the local people do not consider themselves to be impoverished. The research team felt that only through engagement with the communities could they capture the essence of the northern entrepreneurial ecosystem in which the undocumented economy was included.

Another indication of the importance placed on engagement by the research team leaders was the method by which the research ethics was secured. The ethics application included a section entitled Research Involving Aboriginal Peoples that included 20 sub-sections identifying how the research would be conducted in relationship to Articles 9.1 to 9.22 of the Tri-Council Policy for Aboriginal Peoples, Indigenous Peoples, Community, and Community Engagement. Article 9 deals with research involving the First Nations, Inuit, and Métis peoples of Canada, and addresses the requirement for community engagement, the nature of that engagement from a research ethics perspective, and other elements designed to ensure that Indigenous people are fully and meaningfully engaged with any research conducted in their communities (Tri-Council, 2014).

\section{The Research Methodology}

The OECD defines entrepreneurial activity as "the enterprising human action in pursuit of the generation of value, through the creation or expansion of economic activity, by identifying and exploiting new products, processes or markets" (Ahmad \& Seymour, 2008, p. 14). Action research (AR) can be a valuable approach to generating new knowledge when considering the complexities of entrepreneurial activity because it takes into account the multiple perspectives, objectives and opinions of those involved. Participatory action research (PAR) goes beyond the basic research goal of producing useful knowledge to generating change that meets social needs (Herlihy \& Knapp, 2003).

Community-based participatory action research (CBPAR) is a research methodology that adds extra degrees of engagement as it is done for and by communities with a distinct focus on driving action or transformative community enhancement (Brydon-Miller, Greenwood, \& Maguire, 2003; Schmidt, 2009). CBPAR can be a particularly powerful way to better understand 
the broader context of community wellness as it considers the perspectives of the community members themselves. This approach is geared toward empowering communities to engage in a collaborative and respectful dialogue while also seeking transformation to accommodate their needs. CBPAR follows culturally appropriate means to investigate social issues, avoids assumptions that academic researchers are the experts and attempts to reverse unequal power relations between participants and researchers that are associated with traditional research methods (Brydon-Miller et al., 2003; Schmidt, 2009).

The research team chose to apply CBPAR as a way to ensure it directly involved Aboriginal students, community leaders, and other members of northern communities as research partners while acknowledging and respecting their sovereignty (McDonald, 2004). This type of research methodology has frequently been applied in research projects involving Aboriginal communities where it has been shown to produce positive results (Legat, 1994; Masazumi \& Quirk, 1993). Using these methods, Williams (2008) and his colleagues examined Aboriginal economic development practices in British Columbia by engaging chiefs, councilors, and economic development representatives from Aboriginal communities across the province. Tuchak (1997) used a similar approach to investigate community-based economic development by Inuit women. Based on existing academic evidence (Brown, 1985; Hoare, Levy, \& Robinson, 1993), the research team believed that applying CBPAR would be an effective and ethically responsible way to achieve the objectives for their research initiative.

Understanding the cultural and historical context of northern entrepreneurship requires listening to communities' needs and providing a space for them to reflect upon their own experiences while they ponder strategic alternatives for transformation designed to be effective in their local context. Participatory action research can be defined as a "highly reflective, experiential, and participatory mode of research in which all individuals involved in the study, researcher and subjects alike, are deliberate and contributing actors in the research enterprise" (Berg, 2004, p. 196). As a result, CBPAR does not rely on a strict research agenda, but instead, facilitates collaborative relationships and trust between researchers and community members (Edwards, Lund, Mitchell, \& Andersson, 2008).

CBPR is based on a number of principles: acknowledging and addressing the imbalance of power; focusing research on important community issues; accepting multiple world views; fostering empowerment; developing community capacity; working with community members as partners; approaching research as education; and respecting the established protocols of working with Indigenous people. (Koster et al., 2012, p. 198)

One key benefit and an important aspect of CBPAR is community capacity building. The term community capacity building describes a wide range of community enhancing strategies aimed at improving a community's overall well-being. It is broadly defined as a community group's ability to define, reflect, assess and act on concerns of importance to their members (Labonte, 2007; N. Smith, Baugh Littlejohns, \& Thompson, 2001). Such strategies build dynamic social and organizational relationships among individuals, groups, and service providing organizations, and also encourage the sharing of resources. Community capacity building is a process of working with community members to determine their needs and strengths and to 
develop ways of using community strengths to meet those needs (N. Smith et al., 2001).

Utilizing culturally sensitive and community-centered methods will enable Northern communities to take effective and sustainable action toward wealth creation and entrepreneurial priorities most meaningful to them (N. Smith et al., 2001). Community capacity building may become an important bridge between action and positive long-term outcomes for Northern communities.

The BNCAE research team was committed to applying CBPAR methods in its work with its participating communities, particularly as some of those communities had planned but not yet executed initiatives to improve their social and economic capacities (Northern Economic Summit, 2011a, 2011b, 2011c). Whereas CBPAR can involve researchers playing a role in generating change to meet social needs while producing useful knowledge (Herlihy \& Knapp, 2003), in the context of the research team's project, its change-generating role was restricted to providing input into community planning processes only when asked to do so by the community members initiating and managing the projects.

As with the grant application process, initial research planning, and ethics application, the research methodology applied for this project was designed to ensure meaningful engagement with Indigenous communities.

Phase One of the project involved doing telephone and in-person interviews with leaders throughout northern Saskatchewan. The purpose was to seek expert advice regarding how to best engage with the communities to earn their invitations to work collaboratively with them during Phase Two. One important outcome from Phase One was the recurring suggestion that the research team engage with the youth to better understand the aspirations the younger generation had for themselves and for the futures of their communities, and to learn from the youth what the communities can do to satisfy their wants and needs. By embracing this recommendation, the research team also provided a forum for knowledge translation between the youth and the adults in the communities.

The Phase Two data collection methods included two workshops, one with the community as a whole and one with high school students. The community workshop included two focus groups and a request for volunteers to participate in the Photovoice exercise. Photovoice is a photo elicitation method whereby participants share their stories through their photos in relation to open-ended research questions. The volunteers were provided with cameras and research questions, and the date was confirmed for the return visit by members of the research team to interview the Photovoice participants. The high school workshop also included two focus groups along with a peer-to-peer video capture interview exercise the research team called OurV oice. This exercise provided a unique and engaging way for students to record each other on video while asking each other prescribed interview questions in physical settings that they chose. During both of the workshops, respondents indicated on maps what geographic region they considered to be their community. They also used other tools developed by the research team, including checklists and picture cards, to convey their perspectives about the flow of goods and services within and between the communities. These tools were designed to capture the nature of the trade of goods and services in both the documented and undocumented 
components of the northern Saskatchewan economy.

Also informed by the results from Phase One, the research team initiated and implemented a social media-driven communications plan as part of its knowledge mobilization plan. The social media component focused on presenting timely, accessible, and immediately useful information to communities throughout Saskatchewan's north. The information disseminated to communities included some previously existing material from other sources along with outcomes from the research process as they became known. Often the research outcomes were disclosed before the data were fully analyzed and integrated into academic articles and other research documents. The goal was to regularly give something of use back to the participating communities. As asserted by Koster et al. (2012):

any research conducted within a community, regardless of its purpose and methodology, should follow the general principles of Indigenous paradigms, and respect the community by engaging in active communication with them, seeking their permission not only to conduct and publish the research but also with respect to giving results of the research back in ways that adhere to community protocols and practices. (p. 195)

Phase Two data collection began with the Northern Village of Pinehouse Lake, a northern, relatively remote, and primarily Métis municipality accessible by road and located about 500 kilometers north of Saskatoon. The experiences there led to improvements to the processes and tools used in the remaining six communities visited during the fall of 2015 and the winter of 2016. The following sections provide the researchers' perspectives on how the data collection methods and the associated social media-driven communications plans represented Indigenous community engagement and what the outcomes from that engagement were.

\section{Insights from the Community Focus Groups}

The community workshop focus groups were held in the evening and all community members were invited to participate to discuss their community's economic and social capacity with respect to the way entrepreneurship can contribute or is contributing to their concept of the good life, prosperity, and well-being. Research team members guided the flow of discussion during the focus groups by following moderator guides that were continually adapted during the data collection phase to improve upcoming workshops based upon the experiences of those already held. The discussions were based on the personal experiences of the participants and storytelling emerged as a preferred a way of sharing perspectives and engaging in group dialogue.

One research team member reflected upon her experience moderating one of the community focus groups, sharing that "humor and storytelling was a large part of what got the conversations going and made for a very comfortable space for discussion that, at times, led to some fairly sensitive or heavy topics related to the community's capacity to sustain businesses in the north." This process of storytelling removes the researcher-directed approach that 
some focus groups take, and that encourages dialogue catering to what the participants feel the researchers may want to hear. Instead, open conversation and the use of storytelling allowed for organic conversations to flow naturally and provided a rich form of data that helped provide better understanding of participants' perspectives. The organic nature of the dialogue was particularly evident in one case when the participants began telling their stories in their traditional language, with a community member translating for the benefit of the researchers.

During the community workshops, many participants emphasized collectivity as well as tradition, culture, language and land. Overall, the researchers felt the workshop process that enabled storytelling provided community members with ways to build on a conversation that was already happening in the community and allowed for the creation of a more accurate representation of many of the elements of the northern entrepreneurial ecosystem.

\section{Insights from the High School Focus Groups}

The youth workshop focus groups held with Grade 10, 11 and 12 students happened in the afternoon during school hours. As in the community workshops, the research team continually adapted the approaches taken following the initial Pinehouse Lake sessions to improve each successive youth workshop without compromising the content consistency of the data collected across all communities. Students were generally eager to participate in the OurVoice peer-to-peer video interview process the research team developed and refined (described later in this paper), and this appeared to prepare the students to expand on their responses to the video questions during the group discussions. As explained by a researcher who facilitated one of the youth focus groups: "one thing that we discovered was that the youth's stories aligned very well with those of the community and they had an in-depth understanding of the activities of their community." Following the initial Pinehouse Lake youth workshop, the research team introduced a workbook in which students could write down their responses to the discussion topics. This proved to be a productive engagement tool as it gave voice to students who chose not to speak during the focus groups. The responses provided in the workbooks uncovered youth insights and perspectives that might not have otherwise been disclosed.

\section{Insights from Applying Photovoice}

Photovoice is a visual methodology originally developed by Wang and Burris (1997) in which participants share their stories through photographs. Participants are typically asked to express their perspective or represent their community's point of view through their own photography with the aim of uncovering deeper meanings and understanding complex social questions or problems from the perspective of those immediately impacted. Wang and Burris (1997) outlined three main objectives for the Photovoice method: "(1) to enable people to record and reflect their community's strengths and concerns, (2) to promote critical dialogue and knowledge about important community issues through large and small group discussion of photographs, and (3) to reach policymakers" (p. 370). One strength and a key element of Photovoice is that discussions and direction of the interviews are led by the participants themselves since images captured are often personal reflections that are important to participants. As a result, 
participants often lead discussions and become highly involved in the research process by identifying challenges or issues and working towards finding solutions to barriers (Carlson, Engebretson, \& Chamberlain, 2005).

Photovoice has been described as an empowering methodology that encourages all members of a community to engage and have their voices heard through their own photography. Photo elicitation often involves in-person interviews and broader group discussions and analysis about individual photographs with participants, the selection of images that are most important to complete their overarching story, and working together to devise next steps and actions to address issues (Wang, 1999). This next step often includes sharing information with the rest of the community, or reaching out to policy makers and leaders. Storytelling through photography assists in building a narrative with nuanced and rich descriptions that enable better understanding and meaning generation of specific contexts about participants' lives (Poudrier \& Kennedy, 2008). This type of descriptive process as generated through the power and strength of photographic or visual methods might not be achieved through interviews alone.

Photovoice is often combined with or follows the goals of community-based participatory research, particularly with its emphasis on building relationships and partnerships between community members and researchers. The integration of visual techniques with CBPR provides a creative opportunity for members of communities to create knowledge, engage fully in the research process, and work together to address challenges while also celebrating strengths (MacDonald et al., 2011). Absolon and Willet (2005) argued that "the process of telling a story is as much the point as the story itself" (p. 98). In the case of the BNCAE research project, it is apparent that the Photovoice process provided the participants with the opportunity,not available through traditional interviews, to reflect on the research questions posed and frame their responses in ways that provided richer data for the project. In this case, the Photovoice process was the catalyst that helped enrich the stories told.

One of the research team members involved with the Photovoice interview process said, "I think the best part was hearing what people had to say about their photos and how much they engaged in it. I think the open flexible style is really useful in that we ask fairly open questions and let the participants walk us through their photographs." Another team member commented that one of the best aspects of the interview was "participants being able to choose their own photos and explain them on their own terms."

One team member's critique of the process was that they could have used more time to go through the photos with the participants, and revisions should be made to the planned pacing of the interview. He commented, "I would like more time as I felt somewhat rushed." As in most community engaged research, Photovoice requires a significant amount of time, and and participants should be encouraged to take as much time as they need to speak about their photos.

One key theme that came out of the interviews was the concern that development in the region was having a negative impact on the land, and that tradition and culture were being lost. One participant talked about the desire to move back towards a traditional way of life 
without western technology and another spoke about the need to have strong leaders who are inclusive of all members of the community and who encourage people to work together. The following image is an example from one Photovoice participant. While acknowledging that the view would be more pristine without the power lines visible in the picture, the participant described the image as "simply amazing...this is what I wake up to every morning and this is what I would look at as the good life; seeing beautiful scenery of nature every day, all day (...) that would be better... just living off the land, like the older people used to." Common themes that emerged from the Photovoice exercise as well as the community and youth focus groups was the natural beauty of the region and the benefits derived from living off the land.

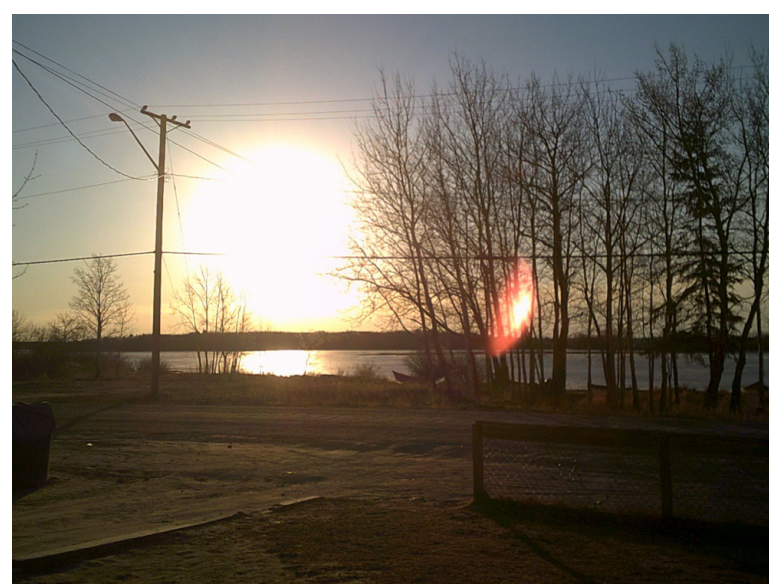

Image 1. Participant Photograph on "The Good Life"

\section{Insights from Applying OurVoice}

In describing the potential use of video to record focus group discussions and interviews, Pink (2007) suggested that researchers must consider the nature of the participants with respect to their familiarity with the media and how it might be part of their culture. Much has changed since she wrote her book, particularly with the proliferation of cell phones with which people regularly record themselves and others. By 2015, when the research featured in this article was conducted, picture taking and video recording in public and among all types of people in groups was so routine in the participating communities in northern Saskatchewan that the research participants would have considered their involvement with video recording (both as a recorder and as someone being recorded) to be commonplace. The research team felt that what the OurVoice method described next was not disruptive to the data collection process, nor an activity that unduly influenced what the respondents said or how they behaved. On the contrary, the BNCAE research team concluded that the use of the OurVoice method empowered the respondents to be more genuine and thoughtful in their responses than might have been the case using alternative data collection methods. The use of peer-to-peer video interviews was an ideal approach that got students interacting and engaging with each other in a comfortable space to prompt discussion about new topics relevant to their community.

The term OurVoice was coined by the BNCAE research team to reflect the enhanced insights into what individuals from communities truly feel when their voices are heard in the free flowing and organic way that occurred when the peer-to-peer video interviews were conducted. The research team thought carefully about the potential benefits and drawbacks from having a researcher interview a youth that they had just met as compared to using the 
OurVoice approach where young people who already know each other interview each other in a familiar setting of their choice using prescribed questions while capturing the exchange on video. After careful consideration the research team anticipated that the youth might be more candid and open with their peers than they would with adult researchers that they had just met. While they recognized the potential risk that little of value would be accomplished if the youth did not comply with the directions when they were on their own with the video cameras, they felt that the potential benefits outweighed the risks.

The OurVoice experiment was a success in that the youth were very candid and on-task when asking and responding to the prescribed research questions while on video. The two questions were as follows: 1) what do you like most about living in your community; and 2) what would make your community an even better place to live? The responses were positive and thoughtful, with very little hesitation to speak candidly and honestly to their peers. The research team members who reviewed the videos were struck by the maturity level demonstrated by the students when asked to provide their insights in response to the questions provided. Moreover, the team members conducting the student workshop received positive feedback about the exercise. One research team member said, "we heard from the teachers and school principal that they have never seen their students as engaged as they were during the workshop and overall they were extremely positive and excited about this experience." Another team member, who had taught in northern Saskatchewan schools, shared what he thought was the most effective and positive outcome from the video exercise and focus group. He indicated that "the way in which the students engaged in the process...they were strongly involved and produced some very thoughtful answers. In contrast, some assignments for students simply do not engage students." The participation level was exceptional, to the degree that when the researchers returned to some communities a few weeks later, students who did not have an opportunity to participate in the initial round asked to participate at that time.

\section{Engagement Outcomes from the Communications Plan}

As part of the project's overarching engagement strategy, a detailed communications plan was developed to continually and meaningfully connect with communities and key stakeholders participating in in the research program. Following a consultation process with northerners and with research conducted by Master of Business Administration (MBA) students from the Edwards School of Business at the University of Saskatchewan, the research team implemented a social media communications strategy using Facebook, Twitter and YouTube. A project website was also maintained to ensure that static information would be readily accessible and available as a stored record of all pertinent research activities. During the data collection phases, radio and local news services were used to promote the community workshops. The research team also began producing and widely distributing quarterly newsletters to provide updates about the project and its outcomes.

There were two main purposes for the communications plan. The BNCAE research team wanted to provide timely and accessible information and updates to community members and other partners, and it wanted to promote the project to encourage other communities 
to become involved with the research initiative. The information sharing component was intended to inform people of the results of the work within their own communities, and also of the outcomes from the research conducted in other communities. It was an opportunity to share social and economic development success stories across the northern part of Saskatchewan and to acknowledge challenges while demonstrating how they were, or could be addressed. The sharing was meant to occur within and across geographic expanses, but also across generations so that youth, adults, and Elders would better understand each other's aspirations and concerns.

The research team needed a communication strategy to encourage communities to actively engage with the research project, and to have them want to invite the BNCAE research team to work with them in their community. The strategy included developing a master contact list of the relatively extensive network of people that members of the research team had personal connections with throughout northern Saskatchewan. As new student research assistants who were from the region joined the research team, they were invited to add their contacts to the list.

While the team took stock of the range and depth of their contacts in Saskatchewan's north, it identified and prioritized a list of communities from which it hoped to collect data. The criteria used to prioritize the list included the desire to work with communities in each of the general regions: northwest, northeast, northcentral, and the far north, a region that can only be reached by airplane. Another criterion was the intention to work with a representative mix of First Nation reserves, in which some people speak the Woodland Cree, Swampy Cree, and Dene languages, and municipalities, some of which include Métis people who speak the Michif language. Reserves fall under Canadian Federal Government jurisdiction and municipalities are under the authority of the Saskatchewan Provincial Government. The team then began a social media, mail, poster, radio ad, and telephone campaign to seek invitations to work with the highest priority communities. This campaign continued until just before each community visit so that it also served to get participants to the community workshops, at which a catered meal was provided as added incentive for community members to attend. By the end of Phase Two, the team had collected data in seven of these high priority communities.

The research team endeavored to establish connections with the right people at the right times. With First Nations communities, the team engaged first with chiefs and band councils to ensure the proper protocols were followed to help build the research partnerships. When engaging with municipalities, they first approached mayors and councils.

In addressing the potential barriers to communication, including language and the potential difficulty in reaching both younger and older people, the BNCAE research team developed potential remedies. One characteristic of Saskatchewan's north was that both adults and youth were active on social media, but Elders were less likely to access information in that way as they generally relied on word-of-mouth or reading or listening to the news for the information they received. While the BNCAE newsletters were only distributed in the English language during Phases One and Two, publications to be shared with communities in later phases of the research program may include translated versions in the Cree and Dene languages. Additionally, 
the team might produce audio recordings of the newsletter in those languages to make the information available to all people in the region. In many cases, community members who used social media helped bridge the technology gap for people who were not as electronically linked in.

For the building relationships part of the communications strategy the team made contacts mostly by telephone unless asked to go to the communities for in-person meetings. In the case of Pinehouse Lake, the research team was invited to, and attended one of the community's Reclaiming our Community (ROC) meetings in the months prior to the data collection visit. That particular meeting helped pave the way for the later trips to the community.

The BNCAE research team engagement activities are represented in the circular flow diagram shown in Figure 1. Those activities represent a continuous cycle of creating new relationships within communities and strengthening existing ones, building trust between the researchers and the community members, working with communities to understand their needs and prepare to collect data, analyzing and reporting the results, and conceptualizing new phases of the research based upon the previous phases. This engagement and communications cycle represents a continuous, fluid, and iterative evaluation of the interactions between the research team and the communities.

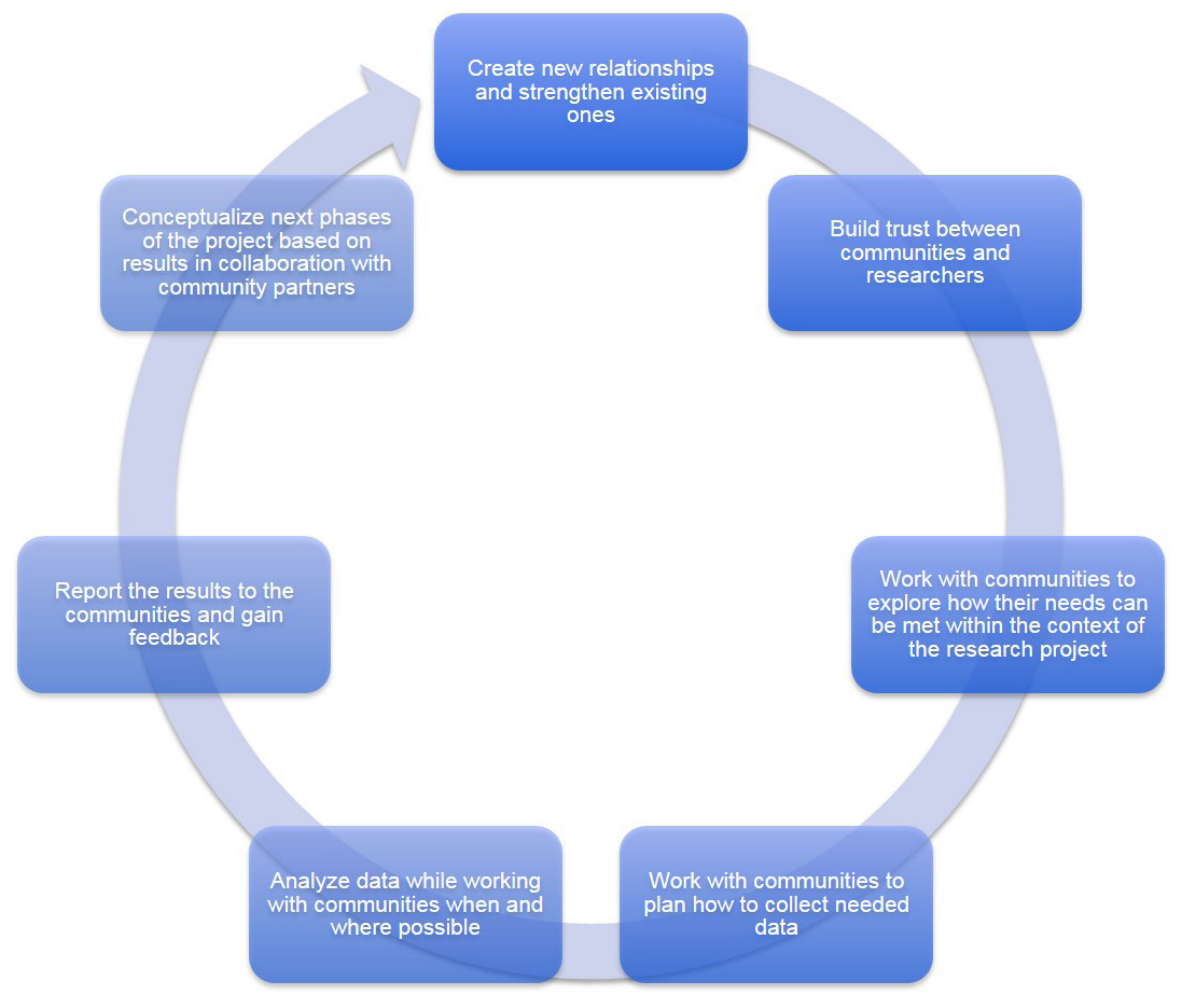

Figure 1: The Research Communications Process: Fluid and Iterative

Engaged Scholar Journal: Community-Engaged Research, Teaching, and Learning 


\section{Conclusion and Future Research}

During a future phase of the research program, the BNCAE team will share what they learned with community members through a video presentation in their communities. This will provide an opportunity for community members to validate the results relative to their community, and suggest revisions as needed.

The general consensus from the BNCAE team members is that their use of an engaged approach with communities helped each of them feel more engaged with the project. The reason for this might be that the particular researchers who were members of this team were attracted to the project in the first place because of its promise of generating true and meaningful value to communities through enhanced levels of engagement with them. As one team member stated, "I am most attracted to research projects like this because I feel much closer to our community participants; they are not just research subjects, they are real people, colleagues even, who can get as invested in the project as we do because they know the outcomes can benefit them,"

Much time and effort went into relationship building with communities. The relationships that research team members built with community members, and especially the youth, indicate the team member level of engagement with the project. A common message from the members who visited the communities was that they "felt like they knew the youth so well" and "spending time in the community was so rewarding." This extra level of engagement helped the researchers build trust and the necessary relationships with the communities. In turn, this trusting relationship paved the way for the storytelling that community members used to share their perspectives and experiences. One researcher noted that she "didn't feel like [she] was facilitating a focus group, [she] felt like [she] was having tea with Elders." This engagement process helped to shift the traditional researcher-participant relationship into one in which researchers and participants were partners working together to discover important insights that would be of use to the communities in which the work was occurring.

The expectation is that, because of the strong and mutually beneficial relationships that were cultivated between the researchers and the communities, new research with an equal degree of engagement will emerge from this project. One highly engaged research project that the team has begun to develop based on outcomes from the current study is focused on leadership in the north.

\section{About the Authors}

Dazawray Landrie-Parker is a Research Associate with ICNGD. She is a proud member of the Métis Nation. Her educational background is in Sociology and Indigenous Studies. She has worked extensively with Métis and First Nation communities with over 10 years' experience 
working in policy development and environmental resource management. Dazawray's professional background is in administration and management, research, legislative policy review and development, and community and industrial consultation and engagement.

Joelena Leader is a Research Associate and Communications personnel at the International Centre for Northern Governance and Development at the University of Saskatchewan. Joelena holds a Master of Arts degree in Sociology and is currently pursuing a $\mathrm{PhD}$ focused on northern innovation. She has over 7 years of research experience with communitybased research projects utilizing arts-based, qualitative and mixed methods approaches in collaboration with First Nations and Métis communities and extensive technical knowledge of qualitative data management and analysis.

Lee A. Swanson (corresponding author) is an associate professor at the Edwards School of Business where he teaches entrepreneurship classes. His research interests include community capacity-building, entrepreneurship, Indigenous entrepreneurship, social entrepreneurship, leadership, and institutional-community engagement. Email: swanson@edwards.usask.ca

\section{References}

Absolon, K., \& Willet, C. (2005). Putting ourselves forward: Location in Aboriginal research In L. A. Brown \& S. Strega (Eds.), Research as resistance: Critical, indigenous and anti-oppressive approaches (pp. 97-126). Toronto: Canadian Scholars' Press.

Ahmad, N., \& Seymour, R. G. (2008) Defining entrepreneurial activity: Definitions supporting frameworks for data collection. OECD Statistics Working Papers: OECD Publishing.

Berg, B. L. (2004). Qualitative research methods for the social sciences (5th ed.). Boston: Pearson.

Blank, R. M. (2005). Poverty, policy, and place: How poverty and policies to alleviate poverty are shaped by local characteristics. International Regional Science Review, 28(4), 441-464.

Brown, L. D. (1985). People-centered development and participatory research. Harvard Educational Review, 55(1), 69-75.

Brydon-Miller, M., Greenwood, D., \& Maguire, P. (2003). Why Action Research? Action Research, 1(1), $9-28$.

Carlson, E. D., Engebretson, J. C., \& Chamberlain, R. M. (2005). The evolution of theory: A case study. International Journal of Qualitative Methods, 4(3), 20-39.

Chilisa, B. (2012). Indigenous research methodologies. Los Angeles: Sage Publications.

Edwards, K., Lund, C., Mitchell, S., \& Andersson, N. (2008). Trust the process: Community-based researcher partnerships. Pimatisiwin: A Journal of Aboriginal and Indigenous Community Health, 2(2), 187-199.

Engaged Scholar Journal: Community-Engaged Research, Teaching, and Learning 
First Nations Centre. (2007). OCAP: Ownership, control, access and possession: First Nations Information Governance Committee, Assembly of First Nations. Ottawa: National Aboriginal Health Organization.

Graeme, C. S. (2013). Indigenous health research and the non-Indigenous researcher: A proposed framework for the autoethnographic methodological approach. Pimatisinin: A Journal of Aboriginal and Indigenous Community Health, 11(3), 513-520.

Herlihy, P. H., \& Knapp, G. (2003). Maps of, by, and for the peoples of Latin America. Human Organization, 62(4), 303-314.

Hoare, T., Levy, C., \& Robinson, M. P. (1993). Participatory action research in Native communities: Cultural opportunities and legal implications. The Canadian Journal of Native Studies, 13(1), 4368.

Koster, R., Baccar, K., \& Lemelin, R. H. (2012). Moving from research ON, to research WITH and FOR Indigenous communities: A critical reflection on community-based participatory research. The Canadian Geographer, 56(2), 195-210.

Labonte, R. (2007). Community, community development, and the forming of authentic partnerships: Some critical reflections. In M. Minkler (Ed.), Community organizing and community building for health (2nd ed., pp. 82-96). Piscataway, NJ: Rutgers University Press.

Legat, A. (1994). Participatory action research in Rae Lakes, NW'T: The traditional government project. Information North, 20, 1-4.

MacDonald, J.-A. M., Gagnon, A. J., Mitchell, C., Di Meglio, G., Rennick, J. E., \& Cox, J. (2011). Include them and they will tell you: Learnings from a participatory process with youth. Qualitative Health Research, 21(8), 1127-1135.

Masazumi, B., \& Quirk, S. (1993). Dene tracking: A participatory research process for Dene/Métis communities. Exploring community-based research concerns for Aboriginal Northerners. Manuscript.

McDonald, J. A. (2004). The Tsimshian Protocols: Locating and empowering community-based research. Canadian Journal of Native Education, 28(1/2), 80-91.

McNaughton, C., \& Rock, D. (2003). Opportunities in Aboriginal research: Results of SSHRC's dialogue on research and Aboriginal peoples. Retrieved from Ottawa, ON:

Northern Economic Summit. (2011a). Projects prioritized for advancement: Athabasca Enterprise Region. Retrieved from http://www.northerneconomicsummit.com/docs/ATHABASCAPROJECTS-LIST.pdf

Northern Economic Summit. (2011b). Projects prioritized for advancement: Boreal West Enterprise Region. Retrieved from http://www.northerneconomicsummit.com/docs/BOREAL-WESTPROJECTS-LIST.pdf

Northern Economic Summit. (2011c). Projects prioritized for advancement: Churchill River Enterprise Region. Retrieved from http://www.northerneconomicsummit.com/docs/CHURCHILL-RIVERPROJECTS-LIST.pdf

Pink, S. (2007). Doing visual ethnography: Images, media, and representation in research (2nd ed.). London: Sage.

Poudrier, J., \& Kennedy, J. (2008). Embodiment and the meaning of the "healthy body": An exploration of First Nations women's perspectives of healthy body weight and body image. Journal of Aboriginal Health, 4(1), 15-24.

Schmidt, H. (2009). Conducting research with First Nations and for First Nations: A reflective study of Aboriginal empowerment within the context of participatory research. York University. 
Schnarch, B. (2004). Ownership, control, access, and possession (OCAP) or self-determination applied to research: A critical analysis of contemporary First Nations research and some options for First Nations communities. Journal of Aboriginal Health, 1(1), 80-95.

Settee, P. (2013). Pimatisiwin: The good life, global Indigenous knowledge systems. Vernon, British Columbia: JCharlton Publishing Ltd.

Smith, L. T. (2012). Decolonizing methodologies: Research and Indigenous peoples (Second Ed.). London: Zed Books.

Smith, N., Baugh Littlejohns, L., \& Thompson, D. (2001). Shaking out the cobwebs: Insights into community capacity and its relation to health outcomes. Community Development Journal, 36(1), $30-41$.

Statistics Canada. (2015). Low income cut-offs. Retrieved from Government of Canada http://www. statcan.gc.ca/pub/75f0002m/2012002/lico-sfr-eng.htm

Tri-Council. (2014). Tri-Council policy statement: Ethical conduct for research involving humans: Government of Canada.

Tuchak, T. (1997). Empowering Inuit women in community-based economic development. Unpublished master's thesis, University of Alberta, Edmonton, AB.

Wang, C. C. (1999). Photovoice: A participatory action research strategy applied to women's health. Journal of Women's Health, 8(2), 185-192.

Wang, C. C., \& Burris, M. A. (1997). Photovoice: Concept, methodology, and use for participatory needs assessment. Health Education \& Behavior, 24(3), 369-387.

Williams, T. (2008). Journey to economic independence: B.C. First Nations' perspectives. Retrieved from Victoria, BC: BC Ministry of Economic Development and First Nations Leadership Council. Retrieved from http://www. cse. gov. bc. ca/Publications/Documents/ FNReportPrintMeg. pdf.

Wilson, S. (2008). Research is ceremony: Indigenous research methods. Black Point, N.S.: Fernwood Publishing. 